\title{
Dureza Rockwell da madeira de três espécies amazônicas submetidas a ensaios de apodrecimento acelerado
}

\author{
Rockwell hardness of the wood of three Amazon species submitted to decay accelerated tests
}

\author{
Diego Martins Stangerlin ${ }^{\mathrm{I}}$ Alexandre Florian da Costa ${ }^{\mathrm{II}}$ Tereza Cristina Monteiro Pastore ${ }^{\mathrm{II}}$ \\ Alencar Garlet ${ }^{\mathrm{III}}$
}

RESUMO

\begin{abstract}
Objetivou-se avaliar o emprego de ensaios de dureza Rockwell na caracterização da biodeterioração das madeiras de Simarouba amara (marupá), Cariniana micrantha (jequitibá) e Dipteryx odorata (cumaru), submetidas ao ataque dos fungos apodrecedores Trametes versicolor (podridão branca) e Gloeophyllum trabeum (podridão parda). Para tanto, corpos de prova de cada espécie amazônica foram submetidos a ensaios de apodrecimento acelerado, de acordo com a ASTM D2017 (2005), durante 20 semanas. A caracterização da dureza Rockwell foi realizada semanalmente até a $4^{a}$ semana e, posteriormente, a cada duas semanas, até a $20^{\underline{a}}$ semana. Adicionalmente, foram determinadas as perdas de massa, conforme critérios estabelecidos pela ASTM D2017 (2005). Quanto aos resultados, destaca-se que a dureza Rockwell pode ser empregada como ferramenta principal na caracterização da biodeterioração da madeira, sendo sensível na predição dos estágios iniciais. Dentre as madeiras amazônicas, o cumaru apresentou a maior resistência natural aos fungos apodrecedores. Com relação aos fungos, a podridão parda atacou mais intensamente as três madeiras amazônicas.
\end{abstract}

Palavras-chave: biodeterioração, podridão branca, podridão parda, madeira tropical, qualidade da madeira.

\section{ABSTRACT}

This study aimed to evaluate the use of Rockwell hardness in the characterization of the biodeterioration of Simarouba amara (marupá), Cariniana micrantha (jequitibá) $e$ Dipteryx odorata (cumaru) woods, which were submitted to decay fungi Trametes versicolor (white rot) and Gloeophyllum trabeum (brown rot). For this purpose, specimens of each Amazon species were submitted to decay fungi, according to ASTM D2017 (2005). The characterization of the Rockwell hardness was performed weekly until the fourth week, and then every two weeks until the twentieth week. Additionally, it was determined the mass loss, according to criteria established by ASTM D2017 (2005). The results indicated that the Rockwell hardness can be used as a primary tool in the characterization of the biodeterioration of wood, being sensitive in predicting the early stages. Among the Amazon woods, cumaru wood showed a greater natural resistance to decay fungi. With respect to decay fungi, brown rot more intensely attacked the three Amazon woods.

Key words: biodeterioration, white rot, brown rot, tropical wood, wood quality.

\section{INTRODUÇÃO}

Apesar de alguns estudos (JESUS et al., 1998; ALVES et al., 2006; CARNEIRO et al., 2009) abordarem a caracterização da resistência biológica de madeiras amazônicas, os resultados ainda são escassos, em função da diversidade de espécies. Além disso, destaca-se que os estudos de apodrecimento acelerado têm mantido o foco apenas nos estágios finais de deterioração, desconsiderando o comportamento da madeira nos estágios iniciais.

A resistência natural a um determinado tipo de fungo é, frequentemente, caracterizada

\footnotetext{
Instituto de Ciências Agrárias e Ambientais, Universidade Federal de Mato Grosso (UFMT), Campus Universitário de Sinop, 78550-000, Sinop, MT, Brasil. E-mail: stangerlin@ufmt.br. Autor para correspondência.

"Faculdade de Tecnologia, Universidade de Brasília (UnB), Campus Universitário Darcy Ribeiro, Brasília, DF, Brasil.

IIIServiço Florestal Brasileiro, Laboratório de Produtos Florestais, Brasília, DF, Brasil.
} 
apenas por meio da perda de massa. De acordo com ZABEL \& MORRELL (1992), EATON \& HALE (1993) e STANGERLIN (2012), deve-se ressaltar que a perda de massa não apresenta a mesma proporção de alteração que as demais propriedades da madeira (físicas, químicas e mecânicas), sendo, desse modo, de pouca utilidade, quando avaliada isoladamente.

Com relação aos estudos da perda de resistência mecânica pelo ataque de fungos apodrecedores, verifica-se que grande parte, mesmo em condições laboratoriais, são realizados com peças de madeira de maiores dimensões, inviabilizando comparações a partir das padronizações da American Society for Testing and Materials - ASTM D2017 (2005). Dentre os ensaios mecânicos, a propriedade de dureza é uma das mais importantes e difundidas para aplicação na qualificação de materiais, em que se destacam, principalmente, os métodos de Janka, Brinell e Rockwell.

Com relação ao método de Rockwell, escassos são os trabalhos aplicados à madeira, porém STANGERLIN (2012) destaca três vantagens da dureza Rockwell em relação aos demais métodos: a) maior exatidão e isenção de erros, já que não exige leitura do tamanho da impressão; b) pequeno tamanho da impressão, evitando fraturas nas amostras; c) não necessita proceder à equalização superficial, visto que, com o emprego da pré-carga, pequenas irregularidades nas amostras são eliminadas.

Desse modo, objetivou-se avaliar o emprego de ensaios de dureza Rockwell na caracterização da biodeterioração das madeiras de Simarouba amara (marupá), Cariniana micrantha (jequitibá) e Dipteryx odorata (cumaru), submetidas ao ataque dos fungos apodrecedores Trametes versicolor (podridão branca) e Gloeophyllum trabeum (podridão parda).

\section{MATERIAL E MÉTODOS}

Para realização desse estudo, utilizaramse seis pranchas, com dimensões nominais de $0,04 \times 0,25 \times 3 m$ (espessura x largura x comprimento), de três espécies amazônicas, marupá, jequitibá e cumaru, sendo obtidas, de forma aleatória, em estabelecimentos madeireiros do Distrito Federal (DF). As pranchas de cada espécie foram anatomicamente identificadas na Área de Anatomia e Morfologia da Madeira do Laboratório de Produtos Florestais (LPF) - Serviço Florestal Brasileiro (SFB), em Brasília, DF. Posteriormente, procedeu-se à confecção dos corpos de prova, da região do cerne, com dimensões nominais de $2,5 \times 2,5 \times 0,9 \mathrm{~cm}$, sendo a menor dimensão no sentido axial.

Os corpos de prova foram submetidos a ensaios de apodrecimento acelerado com dois fungos apodrecedores, sendo um de podridão parda (Gloeophyllum trabeum) e outro de podridão branca (Trametes versicolor). Desse modo, os tratamentos foram estabelecidos na combinação das três espécies amazônicas e dois fungos apodrecedores, totalizando seis tratamentos, sendo utilizados 144 corpos de prova por tratamento. Adicionalmente, para cada espécie, foram avaliados blocos de correção (avaliação da perda de massa operacional), sem ataque de fungos, com 144 corpos de prova.

Os ensaios de apodrecimento acelerado realizaram-se na Área de Biodegradação e Preservação da Madeira do LPF/SFB, ao empregar metodologia adaptada da ASTM D2017 (2005). Em frascos de vidro com tampa rosqueável e capacidade de $150 \mathrm{~mL}$, foram adicionados $70 \mathrm{~g}$ de solo de horizonte B (peneirado em malha de $30 \mathrm{~mm}$ de abertura e com $\mathrm{pH}$ corrigido para 6,0) e $20 \mathrm{~mL}$ de água destilada. Posteriormente, foi inserida uma placa suporte do alburno de madeiras de Cecropia sp. ou de Pinus sp., para desenvolvimento dos fungos de podridão branca e parda, respectivamente, com dimensões nominais de 2,9x3,5x3cm (espessura $\mathrm{x}$ largura $\mathrm{x}$ comprimento). Por fim, os frascos foram autoclavados em temperatura de $120^{\circ} \mathrm{C}$ e pressão de $1 \mathrm{~atm}$ durante uma hora, visando à esterilização e consequente restrição de contaminações.

O meio de cultura foi preparado a base de extrato de malte líquido e, posteriormente, procedeuse à autoclavagem deste, nas condições citadas, durante 20 minutos. Os inóculos dos fungos, de aproximadamente $1 \mathrm{~cm}^{2}$, foram adicionados ao meio de cultura líquido e, em seguida, o material permaneceu em câmara de incubação, com temperatura de $27^{\circ} \mathrm{C}$ e umidade relativa de $70 \%$, por um período de 15 dias, para o desenvolvimento dos fungos.

Após o período de incubação prévia, o meio de cultura foi transferido para o copo de um liquidificador esterelizado, em condições assépticas, sendo então levemente batido, de modo a proporcionar a distribuição homogênea dos micélios dos fungos. A inoculação foi realizada de modo que, em cada frasco, fossem adicionados, sobre a placa suporte e o solo, aproximadamente, $3 \mathrm{~mL}$ do meio 
de cultura. Em sequencia, os frascos permaneceram em câmara de incubação sob condições citadas, até o completo recobrimento do micélio sobre a placa suporte, aproximadamente, 30 dias.

Por fim, adicionaram-se os corpos de prova em cada frasco, que, antes disso, tiveram suas massas obtidas ao permanecerem em estufa de circulação forçada de ar a $50^{\circ} \mathrm{C}$, até atingirem massa constante, e foram esterilizados em autoclave a $120^{\circ} \mathrm{C}$ durante 40 minutos. Os corpos de prova permaneceram em contato com os fungos durante 20 semanas na câmara de incubação.

Semanalmente, até a $4^{\underline{a}}$ semana e, posteriormente, a cada duas semanas, até a 20a semana, foram amostrados 12 corpos de prova, de cada espécie amazônica, submetidos a cada tipo de fungo apodrecedor, além de 12 corpos de prova do bloco de correção. Os corpos de prova foram submetidos à limpeza, para remoção do micélio aderido, e dispostos em estufa de circulação forçada de ar, sob condições citadas, até obtenção de massa constante.

Em cada semana de amostragem, foram determinadas as perdas de massa, conforme critérios estabelecidos pela ASTM D2017 (2005). Subsequentemente, procedeu-se à caracterização mecânica das madeiras deterioradas com auxílio de equipamento medidor de dureza Rockwell, dotado de penetrador esférico de 1/4 de polegada. A carga de ensaio foi aplicada, na seção transversal $(2,5 \times 2,5 \mathrm{~cm})$, em duas etapas distintas, numa primeira, aplicou-se uma pré-carga de $10 \mathrm{kgf}$ e, na segunda, aplicou-se a carga final de teste de 60kgf. Realizaram-se, em pontos distintos, três leituras da dureza Rockwell para cada corpo de prova, sendo o resultado obtido diretamente no mostrador analógico.

Para análise dos resultados de dureza Rockwell, empregou-se a análise de variância com posterior comparação de médias pelo teste de LSD de Fischer $(\mathrm{P}>0,05)$. Adicionalmente, definiramse modelos estatísticos para predição da dureza Rockwell, em função da perda de massa das madeiras deterioradas pelos fungos apodrecedores.

\section{RESULTADOS E DISCUSSÃO}

Mediante análise da figura 1, verificou-se que, de maneira geral, as médias de dureza Rockwell da madeira das três espécies amazônicas não apresentaram estabilização entre a $8^{\underline{a}}$ e $12^{\underline{a}}$ semana de ensaio de apodrecimento, conforme determina a ASTM D2017 (2005). Nesse sentido, pode-se afirmar que o período de ataque dos fungos apodrecedores, determinado pela ASTM D2017 (2005), não foi suficiente para ser aplicado às madeiras em estudo, o que pode sugerir que esse parâmetro deve ser revisto, quando considerado o emprego de ensaios mecânicos.

A partir da 12 a semana, a madeira de marupá foi a única que apresentou estabilização da dureza Rockwell, quando considerados os dois tipos de fungos apodrecedores. A estabilização ocorreu primeiro nas amostras submetidas à podridão parda (14a semana) em relação às atacadas pela podridão branca (16 semana). Porém, é importante ressaltar que tal estabilização ocorreu no momento em que as amostras de marupá apresentaram perda total da dureza Rockwell. Para a madeira de cumaru e jequitibá, verificou-se que a dureza Rockwell manteve-se constante, apenas quando considerada a exposição ao fungo de podridão branca, sendo essa a partir da 12 a semana.

Em relação aos fungos apodrecedores (Tabela 1), de maneira geral, as madeiras submetidas à podridão parda apresentaram menor dureza Rockwell, quando comparadas ao ataque proporcionado pela podridão branca. Diferentemente, GREEN et al. (2004), ao empregarem ensaio mecânico similar (dureza Brinell), não constataram diferenciação da perda de resistência mecânica de amostras de Pinus nigra atacadas por diferentes fungos apodrecedores. Nesse sentido, pode-se considerar que, para o presente estudo, o método de dureza Rockwell foi sensível aos diferentes mecanismos enzimáticos de deterioração. Tal resultado pode ser elucidado em razão da melhor difusão das enzimas dos fungos de podridão parda, em especial, nos estágios iniciais, de modo a provocar, em estágio avançado, o colapso da madeira (ZABEL \& MORRELL, 1992; EATON \& HALE, 1993).

Para as madeiras de jequitibá e cumaru, foi observado que a diferença significativa na redução da dureza Rockwell, devido à exposição entre os fungos de podridão branca e parda, ocorreu a partir da 16 e $8^{a}$ semana, respectivamente. Segundo WILCOX (1978), nos primeiros estágios de deterioração da madeira não se verificam diferenças significativas entre as perdas de resistência mecânica devido às podridões branca e parda. No entanto, para madeira de marupá, pode-se observar que a dureza Rockwell foi significativamente inferior nas amostras submetidas ao fungo de podridão parda durante todo o período do ensaio de apodrecimento, com exceção, basicamente, 


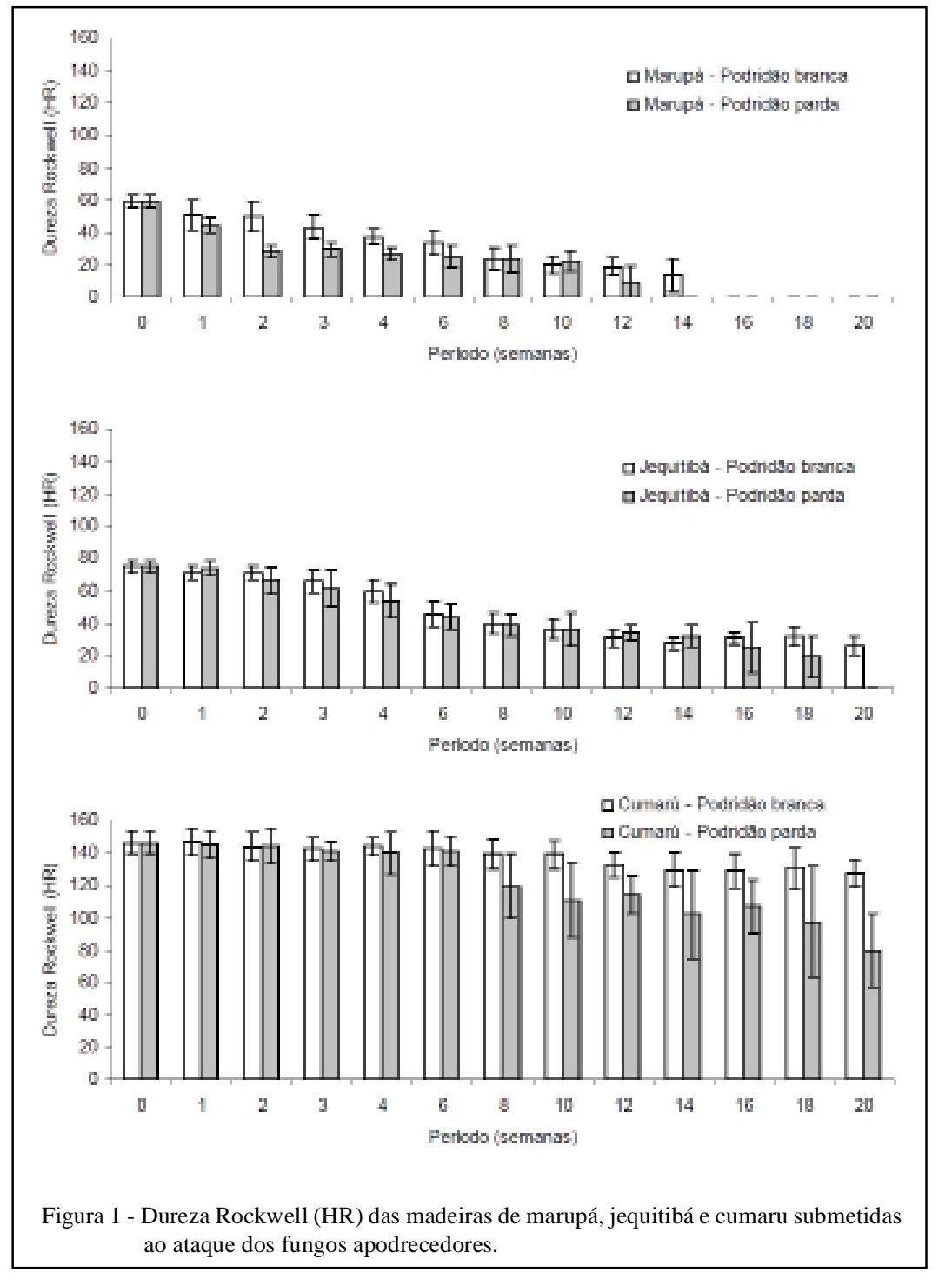

no período final, entre a $16^{\underline{a}}$ e $20^{\underline{a}}$ semana, em que as médias foram iguais estatisticamente, devido à perda total de resistência mecânica.

Com relação à espécie amazônica (Tabela 2), as amostras de cumaru apresentaram maior dureza Rockwell, durante os ensaios de apodrecimento, em relação ao marupá e jequitibá. Tal resultado justificase pela elevada resistência natural da madeira de cumaru (CARNEIRO et al., 2009), a qual está relacionada à alta massa específica básica $\left(0,93 \mathrm{~g} \mathrm{~cm}^{-3}\right)$, bem como ao elevado teor de extrativos $(9,2 \%)$ (STANGERLIN, 2012).

$\mathrm{Na}$ figura 2, pode-se verificar que os modelos de predição da dureza Rockwell, em função da perda de massa, foram satisfatórios, visto que os ajustes preditivos foram significativos a $1 \%$. Para as madeiras de marupá e jequitibá, os melhores ajustes preditivos da dureza Rockwell foram observados quando considerado o ataque do fungo de podridão branca. Entretanto, para o cumaru, verificou-se melhor predição da dureza Rockwell para as amostras expostas à podridão parda.

Ao estabelecer um comparativo entre a dureza Rockwell (Figura 1) e a perda de massa (Figura 3), verificou-se que a primeira foi mais sensível como indicadora da deterioração da madeira em relação à última. Para a madeira de marupá, observou-se que, a partir da $12^{\mathrm{a}}$ semana, a perda de massa, para ambos os fungos, foi superior a $50 \%$. No entanto, ao considerar a dureza Rockwell, podese constatar que perdas de resistência mecânica de, 
Tabela 1 - Comparação das médias de dureza Rockwell entre os ataques dos fungos de podridão branca e parda.

\begin{tabular}{|c|c|c|c|c|c|c|}
\hline \multirow{2}{*}{ Periodo (semanas) } & \multicolumn{6}{|c|}{-------------------Marupá'------------------ } \\
\hline & $\mathrm{PB}$ & $\mathrm{PP}$ & $\mathrm{PB}$ & $\mathrm{PP}$ & $\mathrm{PB}$ & $\mathrm{PP}$ \\
\hline 0 & \multicolumn{4}{|c|}{ 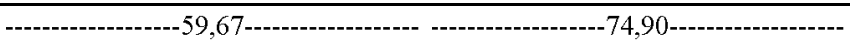 } & \multicolumn{2}{|c|}{ 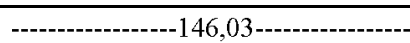 } \\
\hline 1 & $50,42 \mathrm{~b}$ & 44,44 a & 70,92 a & $73,53 \mathrm{a}$ & 146,44 a & 144,69 a \\
\hline 2 & $50,00 \mathrm{~b}$ & $28,39 a$ & $70,75 \mathrm{~b}$ & $66,11 \mathrm{a}$ & $143,56 \mathrm{a}$ & 144,03 a \\
\hline 3 & $43,58 \mathrm{~b}$ & $29,65 a$ & $65,94 \mathrm{a}$ & $61,42 \mathrm{a}$ & $142,35 \mathrm{a}$ & $140,60 \mathrm{a}$ \\
\hline 4 & $37,53 \mathrm{~b}$ & $26,76 \mathrm{a}$ & $60,03 \mathrm{~b}$ & $53,78 \mathrm{a}$ & $143,69 \mathrm{a}$ & $139,66 \mathbf{a}$ \\
\hline 6 & $33,81 \mathrm{~b}$ & $25,78 \mathrm{a}$ & $45,86 \mathrm{a}$ & $43,89 \mathrm{a}$ & $142,64 \mathrm{a}$ & $140,76 \mathrm{a}$ \\
\hline 8 & $23,72 \mathrm{a}$ & $23,81 \mathrm{a}$ & 39,92 a & $38,83 \mathrm{a}$ & $139,31 \mathrm{~b}$ & $119,33 \mathrm{a}$ \\
\hline 10 & $20,00 \mathrm{a}$ & $22,19 \mathrm{a}$ & $36,50 \mathrm{a}$ & $36,39 a$ & $138,67 \mathrm{~b}$ & $110,94 \mathbf{a}$ \\
\hline 12 & $18,93 \mathrm{~b}$ & $9,44 \mathrm{a}$ & $30,86 \mathrm{a}$ & $34,35 \mathrm{~b}$ & $132,37 \mathrm{~b}$ & $113,67 \mathbf{a}$ \\
\hline 14 & $13,57 \mathrm{~b}$ & $0 \mathrm{a}$ & $27,37 a$ & $31,91 \mathrm{a}$ & $129,38 \mathrm{~b}$ & $101,97 \mathbf{a}$ \\
\hline 16 & $0 \mathrm{a}$ & $0 \mathbf{a}$ & $30,81 \mathrm{~b}$ & $24,96 \mathrm{a}$ & $128,73 \mathrm{~b}$ & $106,93 \mathbf{a}$ \\
\hline 18 & $0 \mathrm{a}$ & $0 \mathbf{a}$ & $32,00 \mathrm{~b}$ & $19,36 \mathrm{a}$ & $130,33 \mathrm{~b}$ & $97,44 \mathrm{a}$ \\
\hline 20 & $0 \mathrm{a}$ & $0 \mathbf{a}$ & $26,09 \mathrm{~b}$ & $0 \mathrm{a}$ & $127,54 \mathrm{~b}$ & $79,58 \mathrm{a}$ \\
\hline
\end{tabular}

Em que: PB- Podridão branca; PP- Podridão parda. Dentro de cada espécie amazònica, médias não seguidas na horizontal por uma mesma letra minúscula diferem estatisticamente a $\mathbf{5 \%}$ de probabilidade (LSD Fischer).

aproximadamente, $50 \%$ ocorreram com apenas 6 e 2 semanas de exposição aos fungos de podridão branca e parda, respectivamente. Com relação às amostras de jequitibá, verificou-se comportamento semelhante, em que as perdas de massa na $12^{\mathrm{a}}$ semana foram superiores a 40 e $30 \%$, para a podridão branca e parda, respectivamente, enquanto que as perdas de dureza Rockwell, nas mesmas magnitudes, ocorreram a partir da 6 $6^{\mathrm{a}}$ e 4 semana de exposição aos ensaios de apodrecimento. Ao considerar a perda de massa da madeira de cumaru, apesar da baixa intensidade do ataque dos fungos de podridão branca e parda, não atingindo valores acima de 2 e $6 \%$, respectivamente, foi possível constatar que, ao final dos ensaios de apodrecimento (20 semana), as perdas de dureza Rockwell foram superiores a 12 e $45 \%$.

Segundo ARCHER \& LEBOW (2006), os fungos apodrecedores apresentam como uma de suas principais características a capacidade das hifas ramificarem-se através da estrutura tridimensional da madeira. Tal mecanismo é acompanhado pela produção de enzimas extracelulares capazes de

Tabela 2 - Comparação das médias de dureza Rockwell entre as madeiras de marupá, jequitibá e cumaru.

\begin{tabular}{lccc}
\hline Período (semanas) & Marupá & Jequitibá & Cumaru \\
\hline 0 & $59,67 \mathrm{a}$ & $74,90 \mathrm{~b}$ & $146,03 \mathrm{c}$ \\
1 & $47,43 \mathrm{a}$ & $72,22 \mathrm{~b}$ & $145,56 \mathrm{c}$ \\
2 & $39,19 \mathrm{a}$ & $68,43 \mathrm{~b}$ & $143,79 \mathrm{c}$ \\
3 & $36,61 \mathrm{a}$ & $63,68 \mathrm{~b}$ & $141,48 \mathrm{c}$ \\
4 & $32,14 \mathrm{a}$ & $56,90 \mathrm{~b}$ & $141,67 \mathrm{c}$ \\
6 & $29,79 \mathrm{a}$ & $44,87 \mathrm{~b}$ & $141,70 \mathrm{c}$ \\
8 & $23,76 \mathrm{a}$ & $39,37 \mathrm{~b}$ & $129,32 \mathrm{c}$ \\
10 & $21,09 \mathrm{a}$ & $36,44 \mathrm{~b}$ & $124,80 \mathrm{c}$ \\
12 & $14,18 \mathrm{a}$ & $32,60 \mathrm{~b}$ & $123,02 \mathrm{c}$ \\
14 & $6,78 \mathrm{a}$ & $29,64 \mathrm{~b}$ & $115,67 \mathrm{c}$ \\
16 & $0,00 \mathrm{a}$ & $27,88 \mathrm{~b}$ & $117,83 \mathrm{c}$ \\
18 & $0,00 \mathrm{a}$ & $25,68 \mathrm{~b}$ & $113,88 \mathrm{c}$ \\
20 & $0,00 \mathrm{a}$ & $13,04 \mathrm{~b}$ & $103,56 \mathrm{c}$ \\
\hline
\end{tabular}

Médias não seguidas na horizontal por uma mesma letra minúscula diferem estatisticamente a 5\% de probabilidade (LSD Fischer).

Ciência Rural, v.43, n.4, abr 2013. 


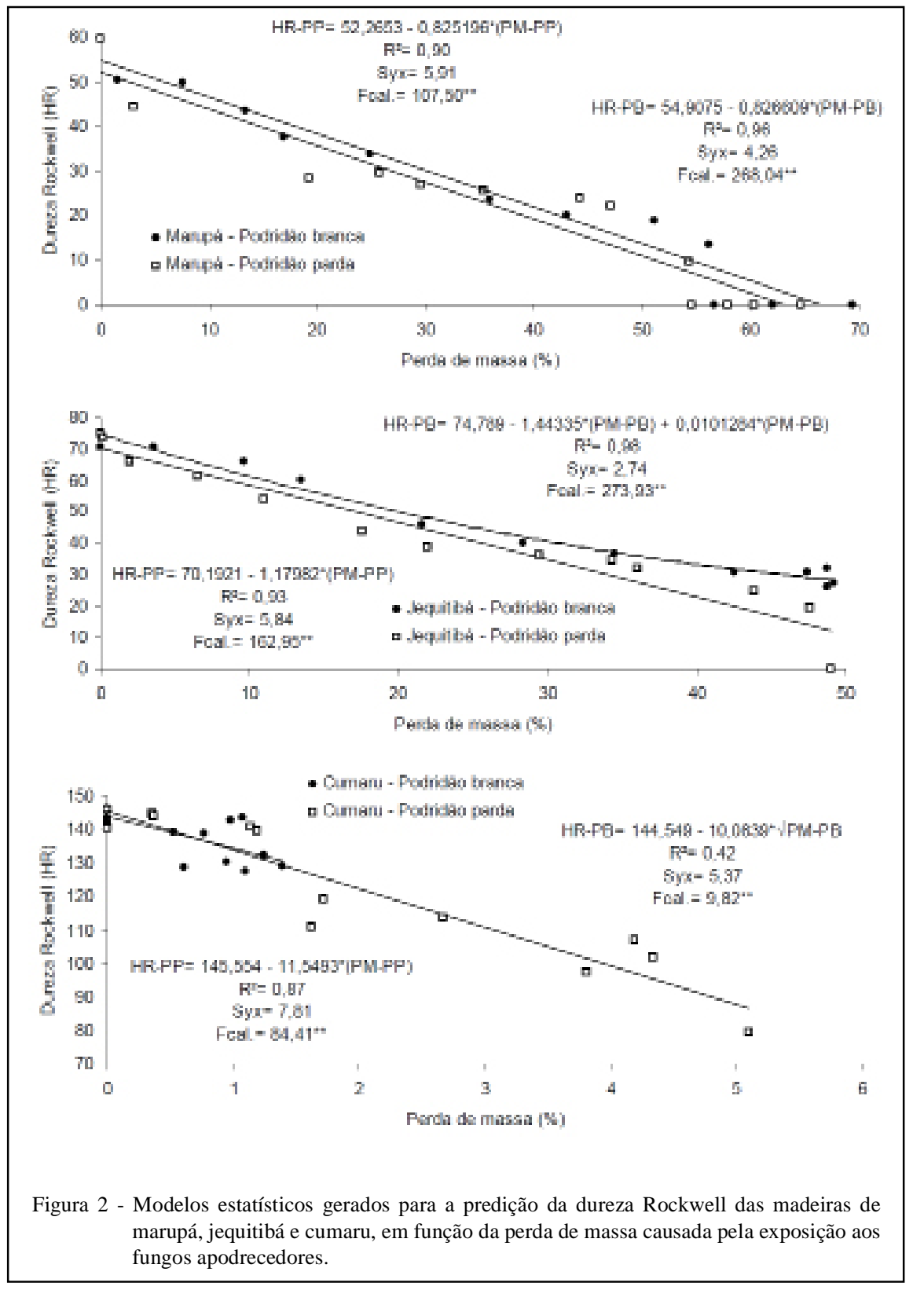

deteriorarem as paredes celulares, de maneira a proporcionarem a fonte de nutrição (polissacarídeos e lignina). Nesse sentido, a difusão inicial das hifas não é acompanhada pela assimilação dos constituintes químicos da madeira, de modo que perdas consideráveis nas propriedades mecânicas ocorrem antes mesmo da madeira apresentar perda de massa, o que torna os ensaios mecânicos ideais para avaliação do grau de ataque de determinado tipo de fungo (STANGERLIN, 2012).

\section{CONCLUSÃO}

Com base nos resultados expostos, pode-se concluir que: a) a dureza Rockwell pode ser empregada como ferramenta principal na caracterização da biodeterioração da madeira, sendo sensível na predição dos estágios iniciais; b) a madeira de cumaru apresentou maior resistência natural aos fungos apodrecedores, quando comparada ao marupá e jequitibá; c) O fungo de podridão parda proporcionou a maior deterioração das três madeiras amazônicas. 


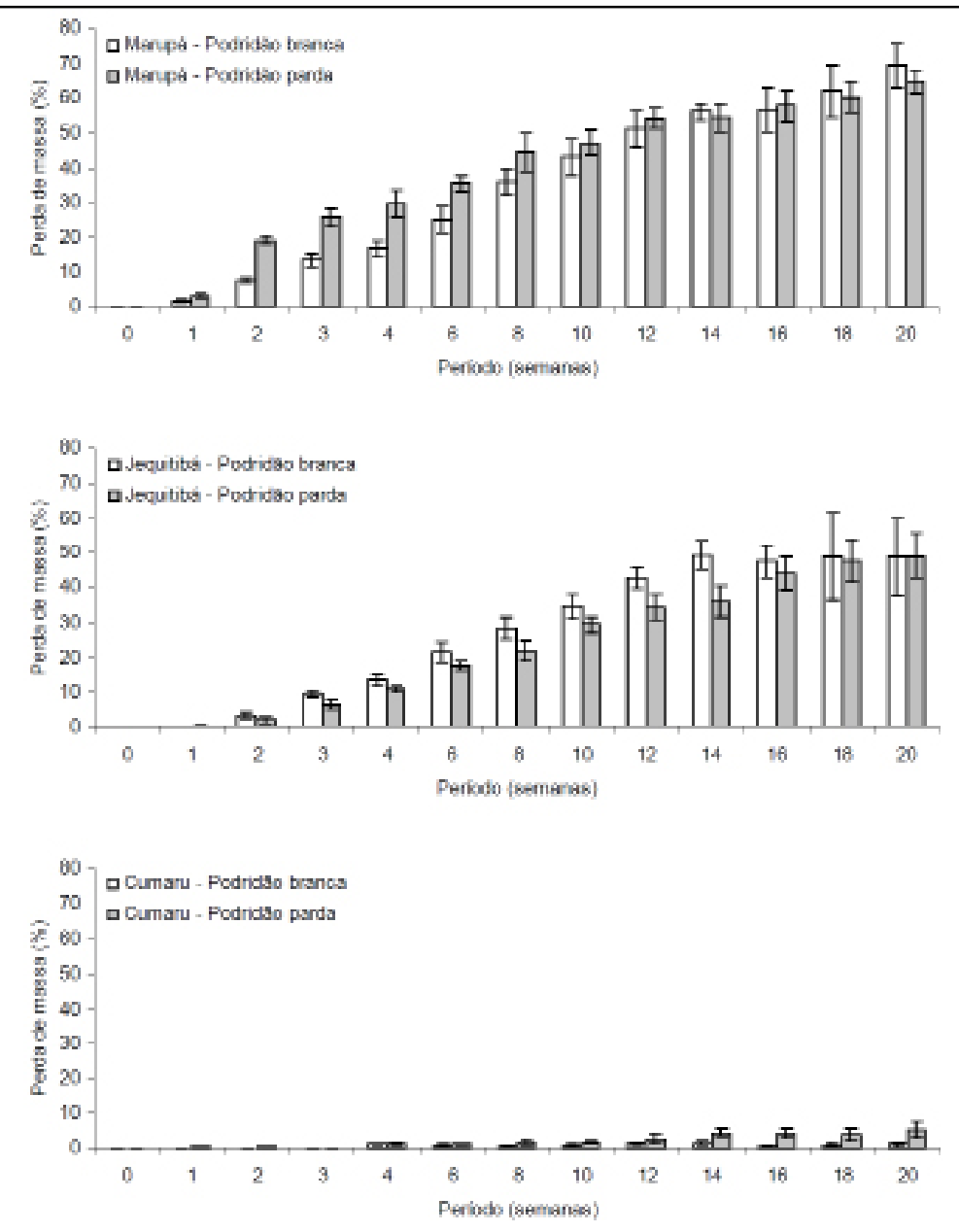

Figura 3 - Perda de massa (\%) das madeiras de marupá, jequitibá e cumaru submetidas ao ataque dos fungos apodrecedores.

\section{REFERÊNCIAS}

ALVES, M.V.S. et al. Resistência natural de seis espécies de madeiras da região amazônica a fungos apodrecedores, em ensaio de laboratório. Ciência Florestal, v.16, n.1, p.17-26, 2006. Disponível em: <http:// cascavel.ufsm.br/revistas/ojs-2.2.2/index.php/cienciaflorestal/article/ view/1884/1130>. Acesso em: 04 mar. 2012.

AMERICAN SOCIETY FOR TESTING AND MATERIALS (ASTM). ASTM D2017: standard method for accelerated laboratory test of natural decay resistance for woods. West Conshohocken: ASTM International, 2005. 5p.

ARCHER, K.; LEBOW, S. Wood preservation. In: WALKER, J.C.F. Primary wood processing: principles and practice. Dordrecht: Springer, 2006. Cap.9, p.297-338.

CARNEIRO, J.S. et al. Decay susceptibility of Amazon wood species from Brazil against white rot and brown rot decay fungi. Holzforschung, v.63, n.6, p.767-772, 2009. Disponível em: <http:// www.degruyter.com/view/j/hfsg.2009.63.issue-6/hf.2009.119/
hf.2009.119.xml?format=INT>. Acesso em: 15 mar. 2012. doi: 10.1515/HF.2009.119.

EATON, R.A.; HALE, M.D.C. Wood: decay, pests and protection. Londres: Chapman \& Hall, 1993. 546p.

GREEN, M. et al. Reduced hardness as an indicator of susceptibility of timbers to attack by Euophryum confine Broun. International Biodeterioration and Biodegradation, v.53, n.1, p.33-36, 2004 Disponível em: <http://www.sciencedirect.com/science/article/pii/ S0964830503001197>. Acesso em: 20 fev. 2012. doi: 10.1016/j. ibiod.2003.07.002.

JESUS, M.A. et al. Durabilidade natural de 46 espécies de madeira amazônicas em contato com o solo em ambiente florestal. Scientia Forestalis, v.54, p.81-92, 1998. Disponível em: <http://www.ipef. br/publicacoes/scientia/nr54/cap07.pdf>. Acesso em: 29 mar. 2012.

STANGERLIN, D.M. Monitoramento de propriedades de madeiras da Amazônia submetidas ao ataque de fungos apodrecedores. 2012. 259f. Tese (Doutorado em Ciências 
Florestais) - Curso de Pós-graduação em Ciências Florestais, Universidade de Brasília, DF.

WILCOX, W.W. Review of literature on the effects of early stages of decay on wood strength. Wood and Fiber Science, v.9, n.4, p.252-257, 1978. Disponível em: <http://swst.metapress.com/ content/e6m0q08085231560/?p=9d2617a8598348599ca8e1964ca c5130\&pi=0 >. Acesso em: 17 mar. 2012.

ZABEL, R.A.; MORRELL, J.J. Wood microbiology: decay and its prevention. San Diego: Academic, 1992. 476p. 